\title{
Aspectos Administrativos da Problemática da Exportação (*)
}

\author{
GeOrge LANDAu
}

\section{I - INTRODUÇÃo}

Conquanto possa êste ensaio parecer, a julgar pelo título, de índole sobretudo econômica, e como tal excluído do âmbito dos estudos técnicoadministrativos, procurar-se-á nêle demonstrar, assim descritiva como crìticamente, que a matéria versada se integra no domínio do planejamento administrativo pròpriamente dito, sob dois ângulos diferentes: primeiramente, por constituir problema da politica governamental no plano orgânico da administração pública; e em segundo lugar, por encerrar numerosos elementos intrinsecos à racionalização do trabalho administrativo.

Sem pretender, portanto, enveredar pelos complexos meandros da teoria econômica, será útil, contudo, para a situação especifica do problema, uma conceituação das premissas, em sua maioria de natureza econômica, sôbre as quais assenta a discussão da matéria. Assim, convém preliminarmente relacionar a problemática da exportação, por sua vez inserida no contexto global do comércio exterior, com a questão fundamental do desenvolvimento econômico do país. Em última análise, a relação é das mais simples: em um sistema, como o nosso, caracterizado por uma aguda deficiência na poupança interna, e ante a relativa carência dé meios de pagamentos provenientes de fontes de crédito externas, nacionais ou internacionais, somente uma exportação intensiva e diversificada pode originar os recursos financeiros necessários: à cobertura das importações essenciais ao desenvolvimento econômico nacional, e, de um modo geral, as fontes de financiamento dêste, seja através de um programa governamental de metas - fruto da cooperação convergente: do Govêrno e da iniciativa privada - seja mediante uma possivel planificação. global de tipo socialista, ou ainda por outro qualquer processo, apenas. teòricamente concebível, em que coubesse à só livre emprêsa promover, dentro em moldes estritamente liberais, o aumento da renda nacional "per capita".

Não se pense que tal concepção seja original com referência à atual conjuntura brasileira. Tradicionalmente tem-se efetuado o progresso econômico do pais à custa dos saldos da exportação, quase unilateralmente consti-

$\left(^{\star}\right)$ Monografia classificada em $3 .^{\circ}$ lugar no Concurso de Monografias do Serviço de Documentaşão do D.A.S.P. 
tuída, de um século para cá, pelo café, em que, partindo de uma situação de quase monopólio, vamos cèleramente perdendo terreno na acirrada competição pelos mercados mundiais, como o atesta a eloqüência glacial das estatísticas. Não se trata, porém, apenas de reconquistar a nossa posição, de há muito perdida. na produção cafeeira internacional, visto ser o café produto primário por excelência, e, por limitado - tanto regional como setorialmente - causa de verdadeiro dualismo na economia nacional. Urge, isto sim, promover a gradativa diversificação da pauta brasileira de exportação, atentas as potencialidades produtivas das regiões de baixo nivel de renda - como o Nordeste ou a Amazônia - bem como a elevação de seus índices, tanto quantitativos (em têrmos de volume e de valor real) como qualitativos.

Aliás, não é apanágio nosso tão grave problema, tipificando, muito ao contrário, senão a totalidade dos países materialmente subdesenvolvidos exportadores que são, todos, de produtos primários e matérias-primas pelo menos os da América Latina, afligidos em maior ou menor grau por problemas semelhantes aos do Brasil. Comprovam-no os numerosos instrumentos, entre convenções e recomendações, adotados por conclaves interamericanos, principalmente como decorrência do recente processo de revitalização econômica da aliança hemisférica, processo êste consubstanciado na Operação Pan-Americana. Tanto mais importante é essa diversificação tendo-se em vista as freqüentes e violentas oscilações de preço a que estão sujeitos, nos mercados compradores, os produtos não manufaturados, o que pode tornar catastrófica a dependência de número limitado de produtos da exportação, dadas as suas repercussões negativas sôbre o volume da receita cambial. Em sintese, é pràticamente possivel equacionar-se o problema da exportação, incentivador da produtividade, com o da viabilidade do desenvolvimento econômico.

Estando tôda a atividade do Govêrno brasileiro - do atual e.dos que o sucederam - necessàriamente prejudicada sôbre tal postulado dinâmico. êste ideal comum que é o rápido crescimento da riqueza nacional dirigida no sentido da elevação do nível de bem-estar social de tôda a população, fácil é compreender que a politica administrativa não poderia deixar de se ocupar do momentoso problema de dar ao mecanismo do Poder Público a estruturação orgânica compatível com a eficiência ótima requerida para a obtenção de recursos financeiros externos, notadamente oriundos de saldos no comércio exterior, capazes de assegurar, a longo prazo, um suprimento regular e crescente de divisas para o financiamento do desenvolvimento econômico nacional. Observe-se que é o aumento das exportações o único meio seguro de baratear as importações, que crescem em valor à medida que se eleva o indice de industrialização do país, pelo menos na fase inicial do esfôrço em prol do desenvolvimento.

Sem embargo, não existe, no arcabouço da Administração federal, qualquer órgão desta natureza. Existe, sim, apenas em embrião, uma entidade sui generis, o Grupo de Trabalho de Fomento à Exportação (FOEXP), do qual se tratará adiante. Não obstante as potencialidades de tal órgão, que longe está de constituir uma repartição burocrática na acepção clássica, permanece efetivamente inaproveitado. $\mathrm{O}$ restante dêste ensaio 
será, pois, dedicado a uma descrição sumária do aparelhamento ao qual pode presentemente o Govêrno recorrer, a fim de atender ao imperativo do fomento à exportação; e a uma análise dos aperfeiçoamentos de que é passível a fórmula atual, visando à sua maior eficiência.

\section{II - O FOEXP COMO TENTATIVA DE SOLUÇÃO}

Ante o imperativo de uma coordenação eficaz e da racionalização das atividades governamentais referentes à exportação - disseminadas por inúmeros Ministérios, autarquias, sociedades de economia mista e outras entidades administrativas - instalou-se em agôsto de 1958, no Conselho do Desenvolvimento, (1) o Grupo de Trabalho de Fomento à Exportação. (2) como um dos 46 grupos semelhantes, de maior ou menor especificidade, existentes no Conselho.

\section{1 - Caracteristicas e finalidades}

$\mathrm{O}_{\mathrm{S}}$ objetivos gerais para os quais foi estabelecido o FOEXP referem-se notadamente, de um lado, à racionalização sistemática da exportação brasileira, e de outro, à adequada reorientação dos investimentos, públicos e privados, inclusive estrangeiros, para o setor da produção exportável, cuja produtividade, outrossim, deveria ser aumentada graças a uma política fiscal e creditícia apropriadada, abrangendo a assistência do Govêrno federal aos Estados e a particulares. Tal assistência incluiria, de maneira específica, a concessão de estímulos especiais à exportação de gêneros alimentícios e principalmente de manufaturas, propiciada por meios adequados de transporte e armazenagem, e se estenderia à redução dos custos internos, à diversificação de mercados compradores e à ampla promoção de vendas ao exterior, através de cooperação entre o Govêrno e as entidades representativas das classes produtoras do país.

Evidentemente, não poderia caber a um órgão colegiado, técnico e informal, de caráter meramente catalítico, em sua essência como é o FOEXP - destituído, portanto, de fôrça politica para implementar as suas recomendações - a responsabilidade de mobilizar tôda a aparelhagem do Executivo federal no sentido de promover a dinamização das exportações. Ainda admitindo-se, por absurdo, que tal houvesse sido a intenção original, estaria o Grupo desprovido do indispensável apoio institucional, porquanto ao Conselho do Desenvolvimento, órgão de planejamento e supervisão, não cabem

(1) O Conselho do Desenvolvimento, órgăo diretamente subordinado à Presidência da República, foi criado pelo Decreto $\mathrm{n}^{\circ} 38.744$, de $1^{\circ}$ de fevereiro de 1956 , modificado pelo Decreto $\mathrm{n}^{\circ} 43.395$, de 13 de março de 1958 , e tem por finalidade o estudo das medidas necessárias à coordenaçăo da política econômica do pais, particularmente no tocante ao seu desenvolvimento econômico; a elaboração de planos e programas visando a aumentar a eficiência das atividades governamentais e a fomentar a iniciativa privada; c de maneira geral, atualmente, a supervisão do programa governamental de metas.

(2) Autorizado em 24 de outubro de 1957 pelo despacho $n^{\circ} 212 / 58.289 / 57$ do MF-EM $\mathrm{n}^{\circ} 1.417$, publicado no Diário Oficial de 23 de outubro de 1957. 
atribuições de ordem executiva, afetas antes às próprias repartições substantivas do Govêrno. E' êste um ponto importante, para o qual convém atentar. De outra parte, pelo fato de estar o Grupo integrando o Conselho, e como tal o escalão mais elevado do Poder Executivo, situa-se o FOEXP em plano privilegiado, não sòmente para a obtenção dos elementos de trabalho de tôda a Administração, como também por permitir um regime de colaboração mais estreita com o Poder Legislativo, e ainda, incidentalmente, com o órgão constitucional independente que é o Conselho Nacional de Economia.

Destarte, pode o FOEXP, em função da sua localização no âmbito da Presidência da República, colaborar, na acepção estrita do têrmo, com as comissões especializadas do Congresso Nacional (como o Grupo de Exportação, da Comissão de Economia da Câmara dos Deputados, e a Comissão Especial de Estudos da Política de Produção e Exportação, do Senado Federal). Quando menos pelo mesmo motivo, de sistemática jurídico-administrativa, se o já não reclamasse o substrato econômico da organização governamental, incumbe ao FOEXP a coordenação dos Grupos Estaduais de Fomento à Exportação (3) os quais, quando estabelecidos, legitimariam a adioão de uma política exportacionista nacional que refletisse o mosaico das necessidades e potencialidades regionais. A êste complexo de mais de mil órgãos oficiais, federais e estaduais, bem assim dos representativos da iniciativa privada, no país e no exterior, convencionou-se, muito expressivamente, denominar Rêde FOEXP. A trama desta Rêde consiste nas interrelações reciprocas dessa multiciplicidade de entidades, tendo por núcleo coordenador e catalizador a Secretaria-Geral do FOEXP, no Conselho do Desenvolvimento. A rêde vincula em um todo orgânico o exportador potencial ou efetivo, no mais remoto rincão do Brasil, aos interessados em seu produto, onde quer que se encontrem no exterior, passando pelas associações de classe, órgãos de contrôle da produção, sistema de transportes, agências aduaneiras ou tributárias em geral, serviços de propaganda, repartições consulares, órgãos operadores de crédito e financiamento, associações de importadores, de atacadistas e varejistas, até chegar ao último consumidor, em qualquer parte do globo. A imagem é sedutora: do Brasil ao mundo, em regime de cooperação, via FOEXP...

\section{2 - Estruturação formal}

Em sua breve existência, já passou o FOEXP por duas fases, condicionadas à orientação imprimida ao Conselho do Desenvolvimento por seu Secretário-Geral. Na primeira etapa, referente ao intervalo entre a criação do Grupo de Trabalho e a mudança na administração do Conselho, ocorrida

(3) Cuja criação foi aprovada pela Recomendação Especial do FOEXP adotada em 27 de novembro de 1958. Aos oficios remetidos pelo Secretário-Geral do FOEXP em $1^{\circ}$ de junho de 1959, sugerindo aos Governadores dos Estados e Territórios Federais a criação de Grupos Estaduais de Fomento à Exportação, responderam até o presente os Governadores do Espirito Santo, Goiás, Mato Grosso, Amazonas, Minas Gerais e Santa Catarina, em sua maioria informando haverem encaminhado o assunto para estudos visando à adoção da medida proposta. 


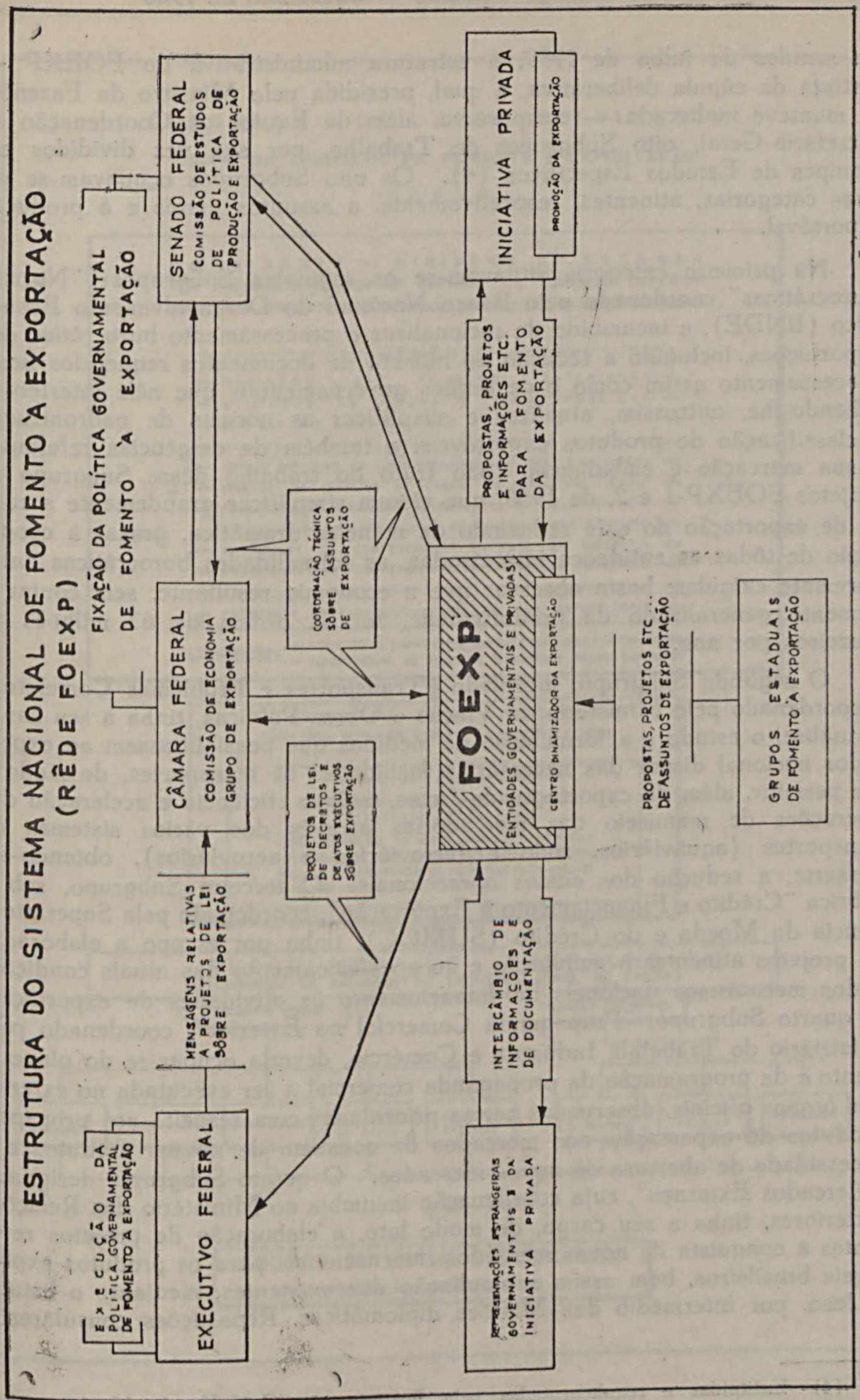


em meados de julho de 1959, a estrutura administrativa do FOEXP distinta da cúpula deliberativa, a qual, presidida pelo Ministro da Fazenda, se manteve inalterada - comportava, além da Equipe de Coordenação da Secretaria-Geral, oito Subgrupos de Trabalho, por sua vez divididos em Equipes de Estudos Específicos (4). Os oito Subgrupos ocupavam-se em duas categorias, atinentes, respectivamente, a assuntos gerais e à produção exportável.

$\mathrm{Na}$ primeira categoria situavam-se os seguintes Subgrupos: "Normas Burocráticas" coordenado pelo Banco Nacional do Desenvolvimento Econômico (BNDE), e incumbido de racionalizar o processamento burocrático das exportações, incluindo a redução do número de documentos requeridos neste processamento assim como o de órgãos governamentais que nêle interferem, cabendo-lhe, outrossim, atualizar e simplificar as normas de padronização e classificação de produtos exportáveis, e também de exigências referentes à sua marcação e embalagem. São fruto do trabalho dêsse Subgrupo os projetos FOEXP-1 e 2, de 1958, que vieram simplificar grandemente a roti na de exportação do café reduzindo de maneira dramática, graças à cooperação de tôdas as entidades interessadas, as formalidades burocráticas anteriormente exigidas; basta observar que a economia resultante, sem contar o aumento generalizado da produtividade, foi da ordem de 63 milhões de cruzeiros por ano.

O segundo Subgrupo, intitulado "Transportes e Problemas Correlatos" e coordenado pelo Ministério da Viação e Obras Públicas, tinha a seu cargo a análise, o estudo e a formulação de medidas que possibilitassem ao expor tador nacional dispor das necessárias facilidades de transportes, de modo a lhe permitir, além da exportação de fretes, melhor eficiência e aceleração das operações de manuseio das mercadorias através dos vários sistemas de transportes (aquaviários, rôdo e ferroviários e aeroviários), obtendo-se, dessarte, a redução dos custos operacionais. O terceiro Subgrupo, sob a rubrica "Crédito e Financiamento à Exportação", coordenado pela Superintendência da Moeda e do Crédito (SUMOC), tinha por escopo a elaboração de projetos atinentes à ampliação e ao aperfeiçoamento das atuais condições e dos mecanismos nacionais de financiamento às atividades de exportação. O quarto Subgrupo, "Propaganda Comercial no Exterior", coordenado pelo Ministério do Trabalho, Indústria e Comércio, deveria ocupar-se do planejamento e da programação da propaganda comercial a ser executada no exterior por órgãos oficiais, observadas certas prioridades com respeito aos principais produtos de exportação, aos mercados de consumo de nossos produtos e à necessidade de abertura de novos mercados. O quinto Subgrupo, designado "Mercados Externos", cuja coordenação incumbia ao Ministério das Relações Exteriores, tinha a seu cargo, de modo lato, a elaboração de projetos referentes à conquista de novos mercados internacionais para os produtos exportáveis brasileiros, bem assim a ampliação dos existentes, mediante o estudo in loco, por intermédio das Missões diplomáticas, Repartições consulares e

(4) Instituidas e regulamentadas pela Portaria $\mathrm{n}^{\circ} \mathrm{SG}-85 / 58$, de 15 de outubro de 1958, do Secretário-Geral do Conselho do Desenvolvimento. 
CONSELHO DO DESENVOLVIMENTO

GRUPO DE TRABALHO DE FOMENTO Ȧ EXPORTACÃO

FOE XP

PRESIDENTE- MINISTRO DA FAZENDA VICE-PRESIOENTE-DIRE,TOR DA CARTEIRA DE COMÉRCIO EXTERIOR SECRETÁRIO GERAL-SECRETÁRIO GERAL DO CONSELHO DO DESENVOLVIMENTO

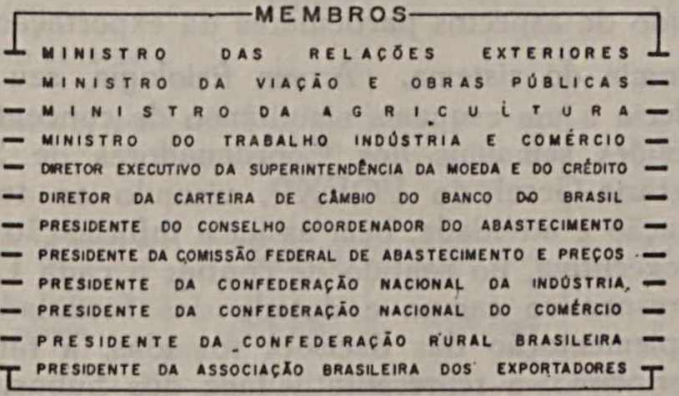

ATRIBUICẼ

ATRIBUIÇOEES: - DECDR SOERE OS PRONETOS ELABOAADOS PELOS SUBGRUPOS

SECRETARIA GERAL DO FOEXP

SECRETÁRIO GERAL: DR. ROBERTO DE OLIVEIRA CAMPOS

ROES DO CONSELHO DO DESENMLVVIMENTO

PRINCIPAIS ATRIBUICÕES

- ASSESSORAMENTO DO SECRETÁAL GERAL DO FOEXP

- COORDENACAO DOS TRABALHOS DOS SUBGRUPOS,

INCLUSINE DA ELABORAC Ä̉O DE ANTEPRONETO DE CRIAÇAO

DE ÓRGÁO COLEGIADO DE FOMENTO A EXPORTACAOO

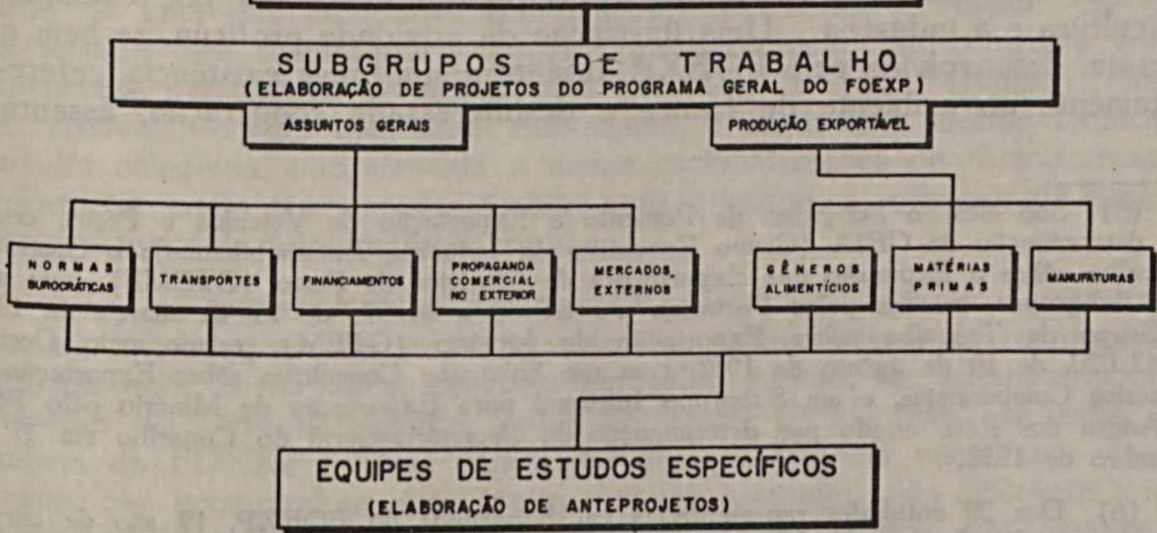


outras agências do Govêrno brasileiro no exterior, das condições de receptividade para os nossos produtos.

$\mathrm{Na}$ categoria dos setores do FOEXP dedicados à produção exportável, distinguiam-se, ainda sob a organização anterior, três Subgrupos de Trabalho, ocupando-se respectivamente, de "Gêneros Alimentícios" (sob a égide do Conselho Coordenador do Abastecimento), de "Matérias-Primas" (coordenado pela Carteira de Comércio Exterior do Banco do Brasil S.A. CACEX) e de "Manufaturas" (êste coordenado pelo Confederação Nacional da Indústria). Paralelamente aos setores do FOEXP, mas sem ligação direta com êstes, conta o Conselho do Desenvolvimento com outros grupos, dedicados ao estudo de aspectos particulares da exportação (5).

Esta, a anatomia do sistema. A sua fisiologia, seu metabolismo, por assim dizer, obedecia a um esquema simultâneo de concentração deliberativa - mediante reuniões semanais dos Coordenadores de Subgrupos com a Equipe da Secretaria-Geral do FOEXP, visando ao traçado de normas comuns de orientação e atividade, bem assim a informação recíproca - e de descentralização executiva, no sentido de confiar a cada Coordenador, especialista em seu respectivo campo e dotado das facilidades administrativas necessárias à implementação das decisões tomadas, a tarefa de pô-las em execução. Em principio, a representatividade dos Subgrupos, sem prejuizo de sua flexibilidade, ficaria assegurada por sua composição, que, sôbre ser diversificada, colimava um equilibrio funcional entre as entidades oficiais e as representativas das classes produtoras (6).

Daí êsse caráter especialíssimo, desafiador de classificações ortodoxas, conferido ao FOEXP, verdadeiro domínio neutro para a conciliação das desavenças porventura existentes entre a politica governamental e os reclamos dos homens de emprêsa e das agremiações classistas. É curioso notar que, não raras vêzes, registrava-se, nas reuniões do FOEXP, maior harmonia entre os representantes do Govêrno e os da iniciativa privada, tomada coletivamente, que entre os de diferentes setores desta, como por exemplo a agricultura e a indústria. Uma ilustração da atividade profícua, se bem que discreta, desenvolvida pelo FOEXP durante a sua breve existência, refere-se justamente ao ambiente de franca e desinteressada cooperação, assentada

(5) São êles: o Subgrupo de Fomento à Exportação de Veículos e Peças, criado. por determinação do GEIA (Grupo Executivo da Indústria Automobilistica); o Grupo de Trabalho sôbre a Expansão das Exportações de Minérios de Ferro (GTEMF), com seus dois Subgrupos, criados pelas Portarias $n^{\circ} \mathrm{S}$ SG-80 e $81 / 57$, de 25 de março de 1957; - Grupo de Trabalho sôbre Exportação de Minério (GTEM), criado pelo Decreto $n^{\circ} 42.020$, de 10 de agôsto de 1957, com um Subgrupo Consultivo sôbre Exportação de Minérios Componentes, e um Subgrupo Informal para Exportação de Minério pelo Pôrto de Angra dos Reis, criado por determinação do Secretário-Geral do Conselho em 17 de setembro de 1958.

(6) Das 29 entidades representadas em Subgrupos do FOEXP, 19 são de caráter governamental, abrangendo Ministérios, órgãos diretamente subordinados à Presidência, a rêde bancária oficial, entidades paraestatais, sociedades federais de economia mista, etc; as 10 entidades restantes, pertencentes à iniciativa privada, representam interêsses classistas nacionais, agremiações técnicas e órgãos consultivos do Govêrno. O conjunto resulta numa seleção de tôdas as instituições brasileiras cuja atividade se prende diretamente à. exportação. 
SÍNTESE DOS RESULTADOS OBTIDOS PELO FOEXP COM A SIMPLIFICACÃO DA BUROCRACIA NAS EXFORTACÕES DE CAFE

\begin{tabular}{|c|c|c|c|c|}
\hline H I S T Ó R I C 0 & $\begin{array}{l}\text { PROJETO } \\
\text { FOEXP-1 }\end{array}$ & $\begin{array}{l}\text { PROJETO } \\
\text { FOEXP-2 }\end{array}$ & $\begin{array}{l}\text { TOTAL } \\
\text { POR PROCESSO }\end{array}$ & $\begin{array}{l}\text { TOTAL } \\
\text { POB ANO }\end{array}$ \\
\hline $\begin{array}{l}\text { Documentos suprimidos ou tornados facultati- } \\
\text { vos...................................... }\end{array}$ & 12 doc. & 2 doc. & 14 doc. & - \\
\hline $\begin{array}{r}\text { Número de vias suprimidas, sem considerar o } \\
\text { carbono................................ }\end{array}$ & 33 vias & 6 vias & 39 vias & 975.000 vias \\
\hline Comprimento das vias suprimidas.............. & $10 \mathrm{mt}$. & $4 \mathrm{mt}$. & $14 \mathrm{mt}$. & 350 kms. \\
\hline Assinaturas abolidas em cada despacho......... & 126 as. & 14 as. & 140 as. & 3.500 .000 as. \\
\hline $\begin{array}{l}\text { (Estaç5es) suprimidas no circuito do processa- } \\
\text { mento (D.F.)............................... }\end{array}$ & 20 est. & - & 20 est. & - \\
\hline $\begin{array}{l}\text { N.o de quilômetros a pé economizados no circui- } \\
\text { to do processamento (D.F.)................... }\end{array}$ & $7,3 \mathrm{~km}$ & - & $7,3 \mathrm{~km}$. & $73.000 \mathrm{kms}$. \\
\hline Pêso do papel economizado.................... & $300 \mathrm{gr}$. & $60 \mathrm{gr}$. & $360 \mathrm{gr}$. & 9 tons. \\
\hline $\begin{array}{l}\text { Economia de papel, despesas de condução, se- } \\
\text { lagem, salários, extraordinários, etc........... }\end{array}$ & Cr\$ 2.500 & $\operatorname{Cr} \$ 25,00$ & Cr\$2.525 & Cr\$ 63 milhб̄es \\
\hline $\begin{array}{l}\text { Aumento de hnras de expediente da FIBAN, } \\
\text { IBC \& Alfândega nos portos cafoeiros......... }\end{array}$ & $12.880 \mathrm{~h} / \mathrm{ano}$ & $6.440 \mathrm{~h} / \mathrm{ano}$ & - & $19.320 \mathrm{~h} /$ ano \\
\hline
\end{tabular}

sôbre concessões mútuas, reinante em todos os trabalhos do Grupo; sòmente tal atmosfera poderia ter propiciado o movimento, ao qual já se fêz alusão, de simplificação burocrática do processamento das exportações. Encarada sob o prisma técnico-administrativo, a iniciativa decerto assume particular significação, porquanto permitiu, com base em apenas dois singelos fatôres - boa vontade e conhecimento de causa - ao poder público, colaborando com os interêsses dos produtores e exportadores, poupar ao sufocante véu da rotina - expressa em superfluidade de papéis, de contrôles, de despachos interlocutórios, de selos e tributos, de desusadas formas de cautelosa fiscalização - uma das atividades econômicas e essenciais à Nação. Se pôde ser vasado êste respiradouro pioneiro na burocracia, em contraste com a deprimente perspectiva delineada pela chamada "Lei de Parkinson", há de ser possivel proceder com igual dinamismo, e segundo a mesma técnica de consulta colegiada, não sòmente a novas racionalizações de fluxogramas da exportação, como também, em âmbito mais dilatado, a reformas de base em outros setores da administração pública.

Ainda no tocante à estrutura formal do sistema de fomento à exportação, cabe descrever agora, em traços suscintos, o esbôço básico da reorganização efetuada após a mudança, ocorrida em julho último, da administração do Conselho do Desenvolvimento, cujo Secretário-Geral, como se sabe, o é também do FOEXP. Mais valerá, talvez, a referência visual aos organogramas que acompanham êste texto; cumpre assinalar, não obstante, que a transformação sofrida pelo Grupo integra-se no quadro mais amplo da reestruturação do Conselho, em cinco grandes setores, um dos quais se refere ao comércio exterior, tanto de importação - no que tange às necessidades do desenvolvimento econômico nacional - como de exportação. O FOEXP, portanto, passa a vincular-se a êste aspecto particular de uma unidade global, 
CD Przsidîncia da repúlica CONSELHO DO DESENVOLVIMENTO
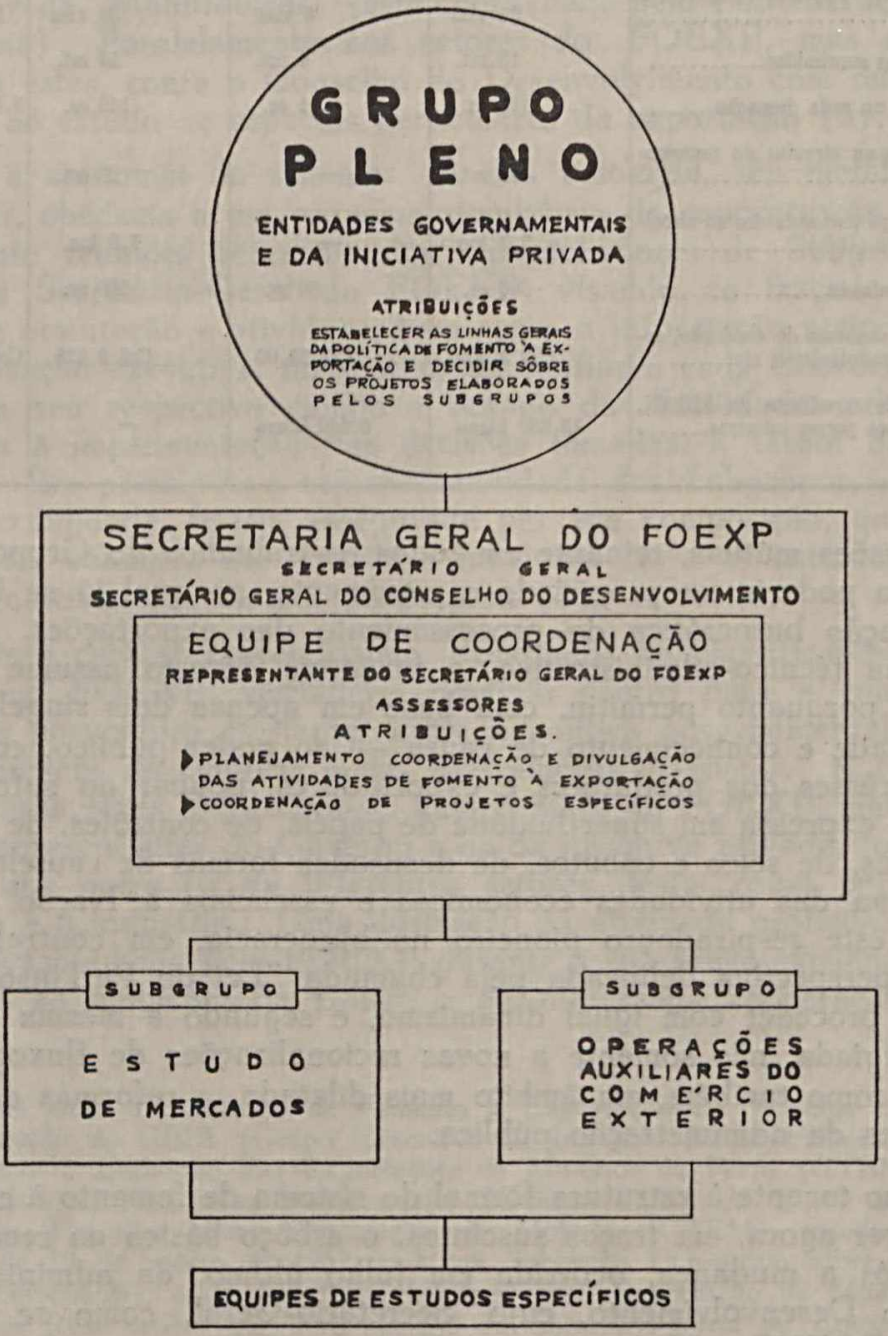
no extremo de uma linha de subordinação administrativa já bastante distendida. Conservando, da vigência do sistema precedente, as atribuições gerais de planejamento, coordenação e divulgação das atividades incentivadoras da exportação, bem assim a de coordenar os projetos específicos que lhe forem submetidos, divide-se a Secretaria-Geral do FOEXP em dois Subgrupos básicos - "Estudo de Mercado" e "Operações Auxiliares do Comércio Exterior" - que, a seu turno, incorporam e consolidam, na qualidade de Equipes de Estudos Específicos, os oito setores anteriormente componentes do Grupo, sem modificações substanciais em seus respectivos objetivos e métodos de trabalho.

\section{3 - Projeções Futuras}

Pôsto isso, seria lícito indagar se, acionado todo êste complexo mecanismo, por ora ainda estático, estará abrangido todo o campo, nada mais restando a fazer senão regular a marcha da poderosa engrenagem. Òbviamente, a realidade é bem diversa. Não só constitui o FOEXP apenas uma tentativa parcial de solução, como, por ser obra pioneira, carece, até certo ponto, da vivência administrativa, do "saber d'experiências feito" que lhe grangearia a compreensão e, forçoso será admiti-lo, o grau de cooperação pública (e política) do qual ainda carece. Urge, sobretudo, lançar os alicerces da empreitada, mediante a aceleração do processo formativo de u'a mentalidade exportadora.

$\mathrm{Na}$ realidade, não pode qualquer conjunto de providências administrativas de alta envergadura prescindir de um substrato psicológico, a diluir as resistências e convocar as energias latentes para a consecução de tarefa máxime quando, como soe ser o caso do fomento à exportação, tendem tais providências a repercutir estratègicamente sôbre a vida econômica do país, podendo mesmo influir sôbre o Chefe do Govêrno na adoção de rumos politicos de âmbito nacional - um esfôrço concertado de molde a mobilizar a produção nacional para a exportação requer profunda penetração na mentalidade dos meios agrícolas, industriais, comerciais e trabalhistas de todo o país, sem omitir, por certo, o próprio Govêrno e notadamente o Poder Legislativo, a quem incumbe fixar a orientação política. Semelhante campanha, que tanto deveria ter de persuasiva como de esclarecedora, só poderia ser levada a bom têrmo por meio de uma agência própria, que, por enquanto, permanece omissa nos projetos oficiais de trabalho. Tal a lacuna à qual se fêz referência.

Em condições ótimas, deveria o FOEXP, para o perfeito desempenho dos encargos que se lhe cometeram, passar da categoria de Grupo de Trabalho para a de Grupo Executivo, segundo o padrão estabelecido para outros núcleos do Conselho do Desenvolvimento. (7) o que lhe lastrearia a autori-

(7) São os seguintes os Grupos Executivos ora existentes no Conselho: da Indústria Automobilistica (GEIA), criado pelo Decreto $n^{\circ}$ 39.412, de 16 de junho de 1956; da Indústria de Construção Naval (GEICON), pelo Decreto n n $^{\circ} 43.899$, de 15 de junho de 1958; para a Aplicação de Computadores Életrônicos (GEACE) pelo Decreto n 45.832 , de 20 de abril de 1959; do Ensino e Aperfeiçoamento Técnico (ENATEC), pelo Decreto $n^{\circ} 46.260$, de 25 de junho de 1959; e da Indústria de Material Pesado (GEIMAPE), pelo Decreto $\mathrm{n}^{\circ} 46.753$, de 26 de agôsto de 1959 . 
dade institucional. Seria êste o desiderato inicial. Por vários motivos que seria ocioso discutir, contudo, não se encontram atualmente reunidas tais circunstâncias ideais. Se, por um lado, não é absolutamente certo que, feito Grupo Executivo, poderia o FOEXP contar com maiores recursos para a execução de seu vasto programa de trabalho, igualmente duvidoso é, de outra parte, que a tão só realização dessa finalidade garantiria o sucesso da operação. Em particular, no que concerne às funções de divulgação, desde o início previstas nos textos básicos do FOEXP, cumpre reconhecer a possibilidade de que um novo elemento orgânico, articulado com o Grupo, quer sob a forma atual dêste, quer sob a que se pretende alcançar, poderia, em determinadas condições, surtir efeitos apreciàvelmente mais proveitosos. A êste novo integrante do sistema nacional da Rêde FOEXP poder-se-ia dar, para efeitos de discussão, o nome de Centro de Informações à Exportação (CIEX). As suas finalidades e características farão objeto do seguinte capitulo.

\section{III - POSSIBILIDADES E ALCANCE DO CIEX}

Do exposto depreende-se que, sendo o Conselho do Desenvolvimento um órgão de assessoramento dentro da Presidência da República, não há que lhe conferir, nem, a fortiori, ao FOEXP, competência de administração substantiva; tal seria o caso ainda que se o transformasse em Grupo Executivo, porquanto permaneceria excessivamente limitada a sua esfera de ação, no tocante às atribuições em principio reservadas a uma entidade do tipo do CIEX. Essencialmente, teria êste funções semelhantes às de um clearinghouse, de uma "câmara de compensação" para intercâmbio sistemático e regular de informações de todo gênero relativas à exportação, podendo, outrossim, aparelhar-se para o desempenho das tarefas paralelas que the fôssem cometidas.

Parece-nos que o mais indicado, para um organismo que satisfaça os requisitos de maleabilidade funcional, prestígio e recursos materiais amplos, bem como facilidade de acesso direto às fontes, seria o seu estabelecimento, sob o patrocínio do Govêrno - e para tanto, coordenado ao FOEXP mas dentro do âmbito das instituições representativas da iniciativa privada. Poderia parecer especulação precoce, a um primeiro relance, o cogitar-se da localização administrativa de uma entidade cuja criação jamais ultrapassou o estágio das conjeturas. Merece atenção, porém, o fato de que a situação funcional do CIEX afetará decisivamente suas potencialidades e que, a seu turno, delas defluirá. Cabe, destarte, precisar a solução pragmática de que se cogita para que possa dar fiel execução aos seus programas de trabalho a entidade ainda por criar.

Inicialmente, convém acentuar que o estabelecimento de uma organização mais ou menos semelhante, em seus aspectos gerais, à que poderia vir a ser - CIEX, vem sendo reclamado há tempos pelas classes produtoras. Ainda recentemente, na III ${ }^{a}$ Conferência Brasileira do Comércio Exterior, realizada no Recife em fins de setembro de 1959, fizeram-se ouvir comentários neste 
sentido; por outro lado, em sua emenda ao projeto $\mathrm{n}^{\circ} 385 / 59$, (8) ora em trânsito pelo Congresso Nacional, o Centro e a Federação das Indústrias do Distrito Federal propuseram, entre outras medidas, a criação de um Conselho Nacional de Propaganda e Expansão Comercial do Brasil, cujas atribuições poderiam, ao nosso ver, ser vantajosamente absorvidas pelo projetado CIEX. Vale recordar, outrossim, que o recente relatório da Missão Especial ao Sudeste da Ásia frisa o imperativo de formação da mentalidade agressiva de exportação, bem assim de ampla divulgação de informações sôbre a produção e exportação brasileiras, sem as quais o país nunca poderá aspirar a tornar-se competidor nos mercados mundiais (9).

Ora, parece óbvio que, pela própria natureza de suas finalidades, embora sendo de comprovada utilidade pública, o CIEX atenderia sobretudo aos interêsses dos exportadores brasileiros, ou seja, da iniciativa particular. Já se arraigou por demais na mentalidade dos homens de emprêsa nacionais, a falsa concepção de que ao Estado, pretenso deus ex machina (contra cujo intervencionismo em seguida protestam), cabe a responsabilidade por tôdas as iniciativas destinadas a beneficiar as fôrças econômicas do país. $\mathrm{Na}$ realidade, o papel que deveria caber ao Govêrno é o de mero deflagrador e suplementador - a neste caso, com todos os recursos ao seu alcance - dos empreendimentos produtivos privados. É princípio pacífico de justiça que, aos beneficiários, cabem os ônus - nada mais lógico, por conseguinte, que às corporações representativas máximas da iniciativa particular corresponda - custeio das projetadas atividades do CIEX, sem prejuizo de eventuais subvenções dos podêres públicos. $\mathrm{O}$ financiamento, por sua vez, implica também, como corolário, no contrôle efetivo da entidade. Em sintese: um Centro de Informações à Exportação. nos moldes abaixos descritos, deveria ser fundado e mantido pelas classes produtoras, em sentido lato, com o apoio integral do Govêrno, mas sem a intervenção direta dêste.

Em estágio tão incipiente de planejamento, seria prematuro fixar a natureza juridica da entidade, seus processos de administração e pormenores da estrutura orgânica. Basta observar que conviria prever, no organograma do CIEX - um esbôço preliminar do qual ilustra êste ensaio - a constituição de uma Junta Diretora ou corpo equivalente, encarregada de formular a orientação geral de seu trabalho, e composta dos representantes de tôdas as instituições, públicas e privadas, participantes, ou colaboradoras, das atividades do Centro. Poderiam ter status consultivo, perante essa Junta, outras entidades, cuja participação técnica nos trabalhos fôsse considerada relevante. As funções do Conselho Fiscal, no qual teriam voto exclusivamente os representantes das organizaçóes responsáveis pelo custeịo do CIEX, são de intuitiva compreensão. A Secretaria Executiva teria sob sua direção a efetiva gerência das operações substantivas da entidade, convindo que seu

(8) O projeto $n^{\circ} 385 / 59$, oriundo do Executivo, reorganiza o Ministério das Relações Exteriores. A referida emenda foi encaminhada à Câmara dos Deputados e integralmente publicada no Jornal do Comércio do Rio de Janeiro em 20 de setembro de 1959.

(9) Cf. Hugo Gouthier de Oliveira Gondim, Relatório da Missão Especial ao Sudeste da Asia, apresentado aos Ministros das Relações Exteriores e da Fazenda, 1959 (multigr.) - pp. 20 e 137 a 145 . 
titular, escolhido de comum acôrdo pelas organizações participantes, reunisse as qualidades de liderança, traquejo e proficiência requeridas para tão importante cargo.

No que tange ao funcionamento dos setores técnicos do projetado CIEX, cumpre salientar que se trataria sobretudo de órgão técnico, desprovido de encargos político-normativos, e destinado a servir por igual a dois públicos: internamente, divulgando entre produtores e exportadores brasileiros os informes destinados a proporcionar-lhes conhecimento do mercado exterior, e estímulo para a exportação dos produtos nacionais; externamente, favorecendo a conquista de novos mercados para tais produtos, bem assim a manutenção e ampliação dos atuais, inclusive familiarizando os importadores estrangeiros com a sistemática brasileira do comércio exterior. Mais especìficamente, caberiam ao CIEX, como entidade executora, em têrmos práticos, do programa do FOEXP no referente à informação, as funções básicas a seguir discriminadas.

- Manutenção de cadastros de importadores estrangeiros, exportadores brasileiros e outras entidades integrantes da Rêde FOEXP;

- compilação, análise e interpretação, à base dos dados coletados no país ou obtidos, por qualquer fonte, no exterior, de elementos estatísticos, cotações cambiais e informações de outra qualquer natureza versando matéria de interêsse potencial. lato sensu, para os, exportadores brasileiros ou os importadores estrangeiros de produtos nacionais;

- proporcionar recursos técnicos para auxiliar, em seus empreendimentos, organizações interessadas em promover por qualquer meio lícito a exportação de produtos brasileiros, mediante a criação de oportunidades para transações comerciais internacionais em que participem ativamente emprêsas brasileiras;

- estabelecimento de contatos com tôdas as representações brasileiras no exterior, bem assim com as entidades estrangeiras sediadas no Brasil, que, a qualquer título, possam participar do comércio internacional do país, no sentido de assegurar um suprimento constante de noticias, material de documentação, informes e outros dados aproveitáveis pelo CIEX;

- articulação de contatos com os organismos referidos no item anterior. e ainda com tôdas as agências e os veículos noticiosos e informativos, quer de imprensa escrita, quer de difusão áudio-visual, nacionais e estrangeiros, que, em escala universal, possam difundir com presteza e eficiência os elementos de divulgação que lhes fornecer o CIEX, com referência às possibilidades brasileiras de produção e exportação;

- organização de campanhas publicitárias para, de um lado, estimular a formação, no Brasil, de u'a mentalidade agressiva de exportação, e, de outra parte, promover no exterior o incremento à receptividade para os produtos brasileiros;

- orientar tècnicamente a participação de exportadores brasileiros em feiras, exposições e certames internacionais congêneres, e coordenar mediante critérios seletivos articulados com os serviços oficiais competentes, a participação do Brasil nos que oferecerem melhores perspectivas; 


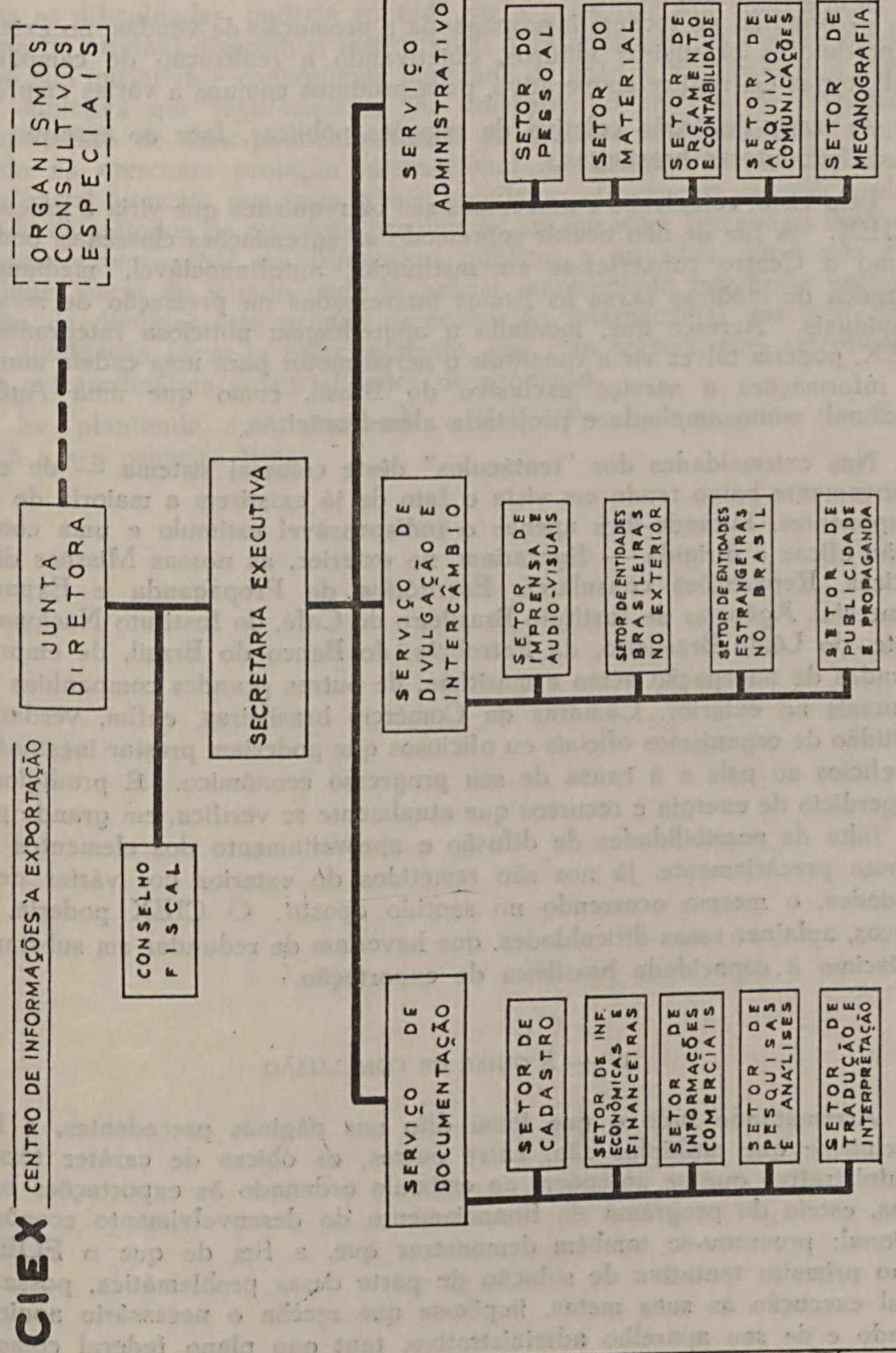


- preparar publicações, inclusive manuais, destinadas a ilustrar, para uso interno, as facilidades existentes para a exportação, e, no exterior, a informar aos interessados sôbre tudo o que necessitem saber com respeito à exportação brasileira;

- orientar, no tocante à propaganda e promoção de vendas, no exterior, os produtores brasileiros idôneos, objetivando a realização de campanhas publicitárias em regime cooperativo, para produtos comuns a várias emprêsas;

- servir de órgão coletivo de relações públicas, face ao exterior, das classes produtoras brasileiras.

Pelo visto, complexos e numerosos são os requisitos que viria a preencher - CIEX. A fim de não onerar sobremodo as agremiaçóes classistas, poderia mesmo o Centro converter -se em instituição autofinanciável, mediante $a$ cobrança de módicas taxas às firmas interessadas na prestação de serviços individuais. Acresce que, montada a aparelhagem noticiosa integrante do CIEX, poderia talvez vir a constituir o nervo motor para uma cadeia mundial de informações a serviço exclusivo do Brasil, como que uma Agência Nacional, muito ampliada e projetada além-fronteiras.

Nas extremidades dos "tentáculos" dêste colossal sistema - de custo relativamente baixo tendo em vista o fato de já existirem a maioria de seus componentes, faltando-lhes apenas o indispensável estímulo e uma coordenàção eficaz e dirigida - figurariam, no exterior, as nossas Missões diplomáticas, Repartições consulares, Escritórios de Propaganda e Expansão Comercial, Agências do Instituto Brasileiro do Café, do Instituto Nacional do Mate, do Lóide Brasileiro, da Petrobrás, do Banco do Brasil, de emprêsas privadas de navegação aérea e marítima, de outras grandes companhias com sucursais no exterior, Câmaras de Comércio brasileiras, enfim, verdadeira multidão de organismos oficiais ou oficiosos que poderiam prestar inestimáveis benefícios ao país e à causa de seu progresso econômico. É prodigioso o desperdício de energia e recursos que atualmente se verifica, em grande parte por falta de possibilidades de difusão e aproveitamento dos elementos que, embora precàriamente, já nos são remetidos do exterior por várias dessas entidades, o mesmo ocorrendo no sentido oposto. O CIEX poderia, aos poucos, aplainar essas dificuldades, que haveriam de redundar em substancial acréscimo à capacidade brasileira de exportação.

\section{IV - À GUISA DE CONCLUSÃO}

Arrematando tudo o que ficou dito nas páginas precedentes, é lícito concluir-se que múltiplos são, entre outros, os óbices de caráter técnicoadministrativo que se antepõem ao estimulo ordenado às exportações brasileiras, esteio do programa de financiamento do desenvolvimento econômico nacional; procurou-se também demonstrar que, a fim de que o FOEXP, como primeira tentativa de solução de parte dessa problemática, possa dar cabal execução às suas metas, impõe-se que receba o necessário apoio dc Estade e de seu aparelho administrativo, tant ono plano federal como no local. 
Ao mesmo tempo causa e efeito da formação, no país, de u'a mentalidade favorável ao incremento de nosso comércio exterior, o Centro de Informações à Exportação, cuja criação aqui se alvitrou, sem pretender sanar tôdas as dificuldades, poderia contudo vir a constituir útil contribuiçãn, sob forma de original dispositivo institucional, que restituisse às classes produtoras a sua iniciativa e conseqüente liberdade de ação, e ao Govêrno a atribuição supletiva que legitimamente the compete, no sentido de favorecer ○ cumprimento de uma política nacional de fomento a exportação. Colaborando na crescente projeção internacional do Brasil, viria o CIEX, sem substancial aumento nos ônus atuais, coordenar eficazmente - com a plasticidade de métodos de operação peculiar às organizações comerciais dinâmicas - uma extensa rêde de organismos públicos e privados, entre nós e em qualquer parte do mundo onde se acham representado interêsses nacionais, a fim de divulgar êste grande desconhecido internacional que é o Brasil. Tal divulgação far-se-ia principalmente, mas não apenas, com referência às suas extraordinárias potencialidades de produção.

Se "plantando, dá!", plantemos; o FOEXP seria a semente, e o CIEX quiçá o seu primeiro fruto. 